\title{
AEROPUERTO INTERNACIONAL KING KHALED. RIYADH/ARABIA SAUDITA
}

\author{
(KING KHALED INTERNATIONAL AIRPORT. RIYADH/SAUDI ARABIA)
}

\author{
Said Yousef Amin, Mohammed N. Dahman y Saad M. Tassan \\ Hellmutt, Obata \& Kassabaum \\ Harry Weese y Asociados
}

\section{RESUMEN}

El aeropuerto internacional King Khaled de Riyadh es el nuevo acceso aéreo a la capital de Arabia Saudita y al corazón del reino. Es el centro del sistema de transporte aéreo nacional y está proyectado para atender las demandas de tráfico aéreo nacional e internacional, de crecimiento rápido, en la región de Riyadh. Su diseño se adapta a las tradiciones islámicas y armoniza con la belleza natural del desierto.

\section{Conistrucción del aeropuerto}

Estratégicamente situado cerca del centro de la península arábiga, Riyadh es un centro regional y económico y la sede del Gobierno del Reino de Arabia Saudita. Es un importante centro comercial y de distribución que facilita comunicación aérea y por carretera entre las principales zonas industriales de Jeddah en la zona occidental y Damman-Dhahran en el Golfo de Arabia.

La expansión de la capital a lo largo de los años desbordó la capacidad del aeropuerto internacional existente, por lo que el gobierno decidió construir un nuevo aeropuerto en una zona situada a 35 kilómetros al norte de la ciudad, donde no plantearía problemas para el crecimiento de la misma.

Las características del aeropuerto internacional King Khaled son su facilidad de acceso por medio de carreteras de llegada y de salida separadas, sus amplias zonas

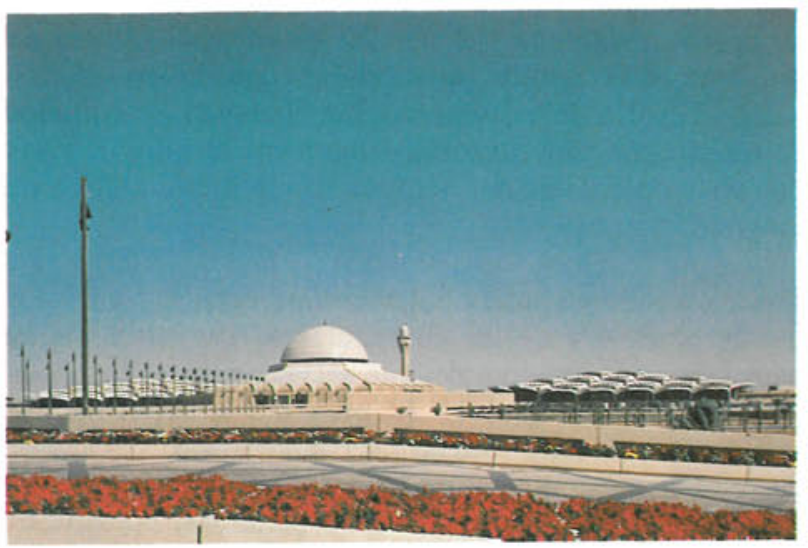

\section{SUMMARY}

King Khaled International Airport in Riyadh is the new access to the Saudi Arabia capital and to the heart of the Kingdom. It is the center of the national air transport and it has been planned to attend all the needs of the national and international air traffic. which has a fast growth in Riyadh zone. Its design is adapted to the islamic traditions and harmonizes with the natural beauty of the desert.

de aparcamiento y el uso de puentes de carga para eliminar el transporte en autobús entre las terminales y el avión. El proyecto del aeropuerto está calculado para una expansión modular y económica como consecuencia de las necesidades del crecimiento del Reino.

Algunos de los conceptos incorporados en el proyecto del aeropuerto son los siguientes:

- Los edificios reflejan las últimas tendencias en proyecto de aeropuerto, diseño, operaciones y tecnologia.

- Los edificios reflejan el carácter y la influencia cultural islámica y satisfacen los requisitos del medio desértico ambiente.

- La estética arquitectónica establece una jerarquía adecuada entre los tipos de construcción del aeropuerto. El aspecto de los diferentes tipos de edificio

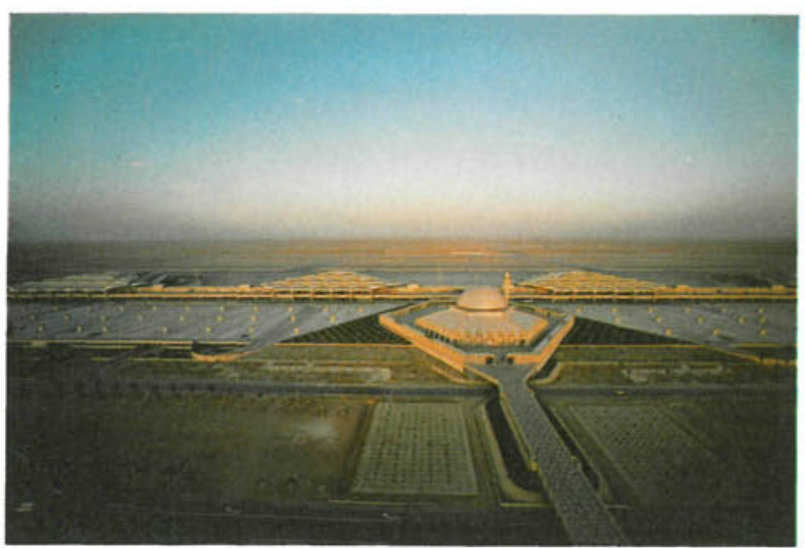




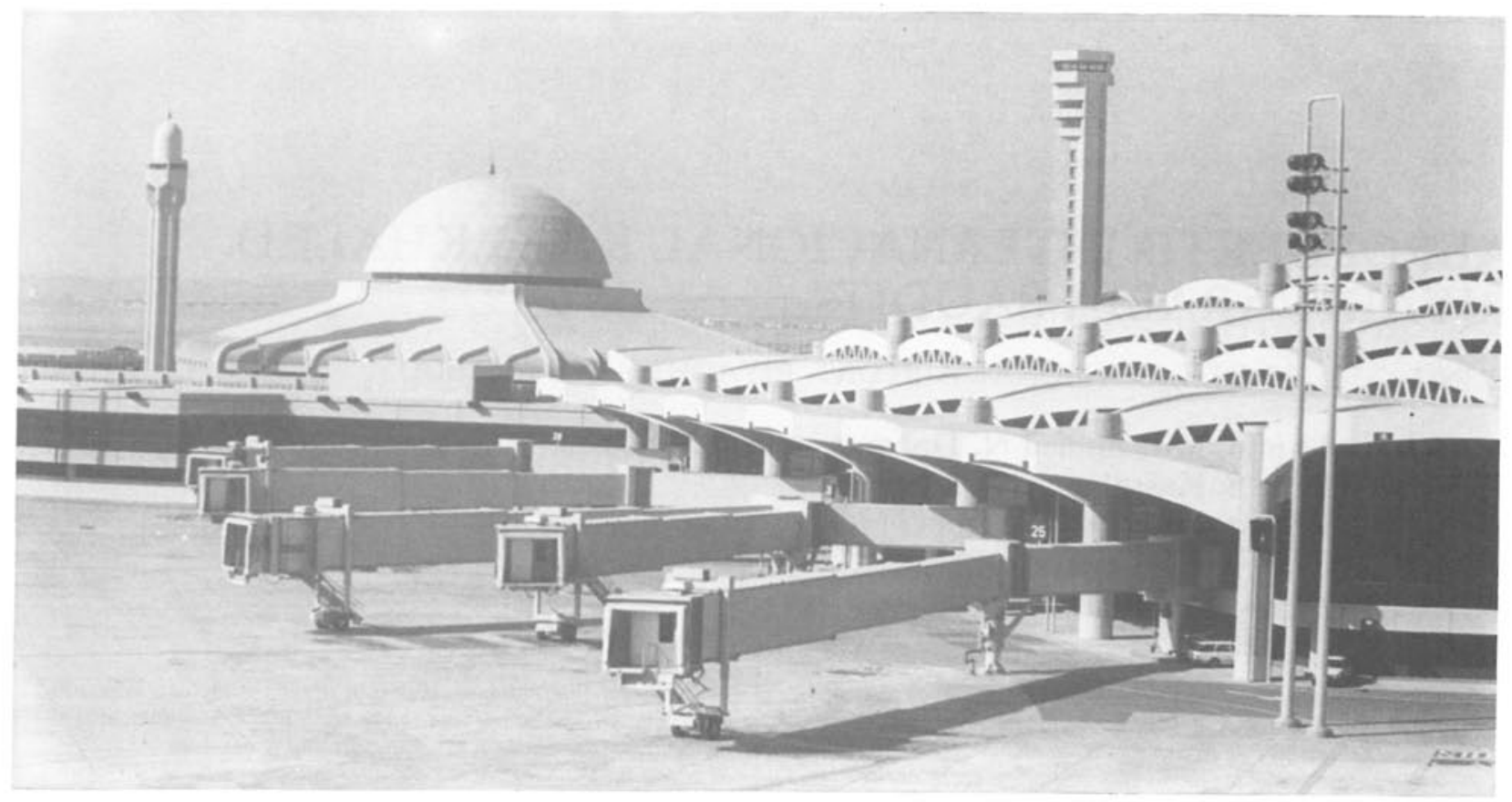

queda unificado mediante el uso coherente de materiales y detalles arquitectónicos.

- En la medida de lo posible se han normalizado los sistemas de construcción, componentes, detalles y materiales y por consiguiente se han simplificado la construcción, el mantenimiento y la reparación.

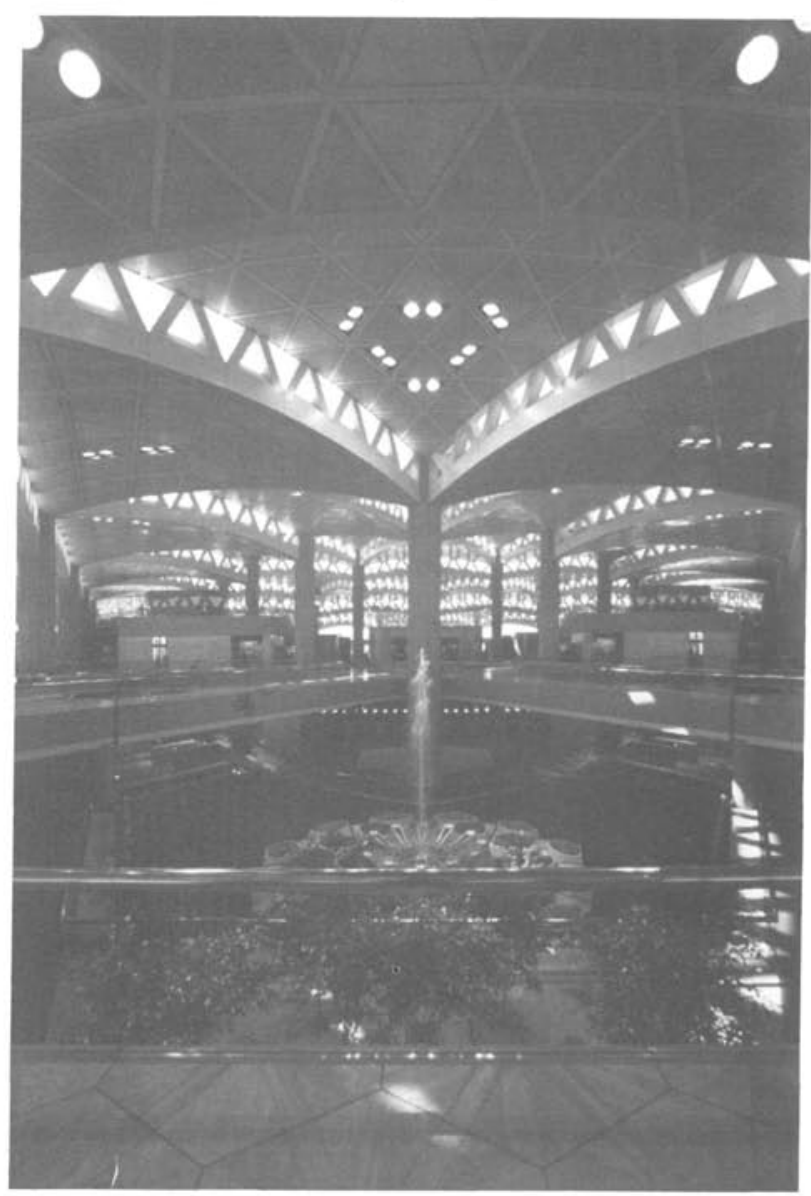

- La disposición del emplazamiento y los planos de los edificios permiten un crecimiento futuro.

- El sistema de transporte evita congestiones y minimiza los conflictos entre los vehículos de servicio y los coches privados.

- Las instalaciones requieren un minimo de mantenimiento y reparación.

— Los sistemas de seguridad y salvamento son los más modernos y eficaces disponibles.

- Todas las instalaciones han sido proyectadas para ser funcionales y de fácil mantenimiento.

Tanto la ubicación como el diseño del aeropuerto son compatibles con el medio natural y cultural del reino. $\mathrm{Su}$ ubicación minimiza el ruido, la contaminación del aire y los problemas de seguridad para la ciudad de Riyadh y resulta acorde con el crecimiento previsto de la ciudad. Su diseño se adapta a las tradiciones islámicas y armoniza con la belleza natural del desierto.

Las instalaciones del aeropuerto ocupan una superficie de aproximadamente 12 por 20 kilómetros. Dentro de este área se encuentran distribuidas todas las instalaciones principales del aeropuerto, que incluyen los edificios de terminales, una mezquita, una torre de control y las dos pistas paralelas del aeropuerto, de 4.200 metros de longitud.

Las instalaciones adicionales comprenden los edificios del aeropuerto y de las compañias aéreas, edificios de usos generales, un complejo de servicios de vuelos especiales y aviación general. El proyecto también incluye pistas de circulación, superficies de descarga, sistema de carreteras y una comunidad habitacional completa e independiente para alojar a 3.000 personas, constituida 


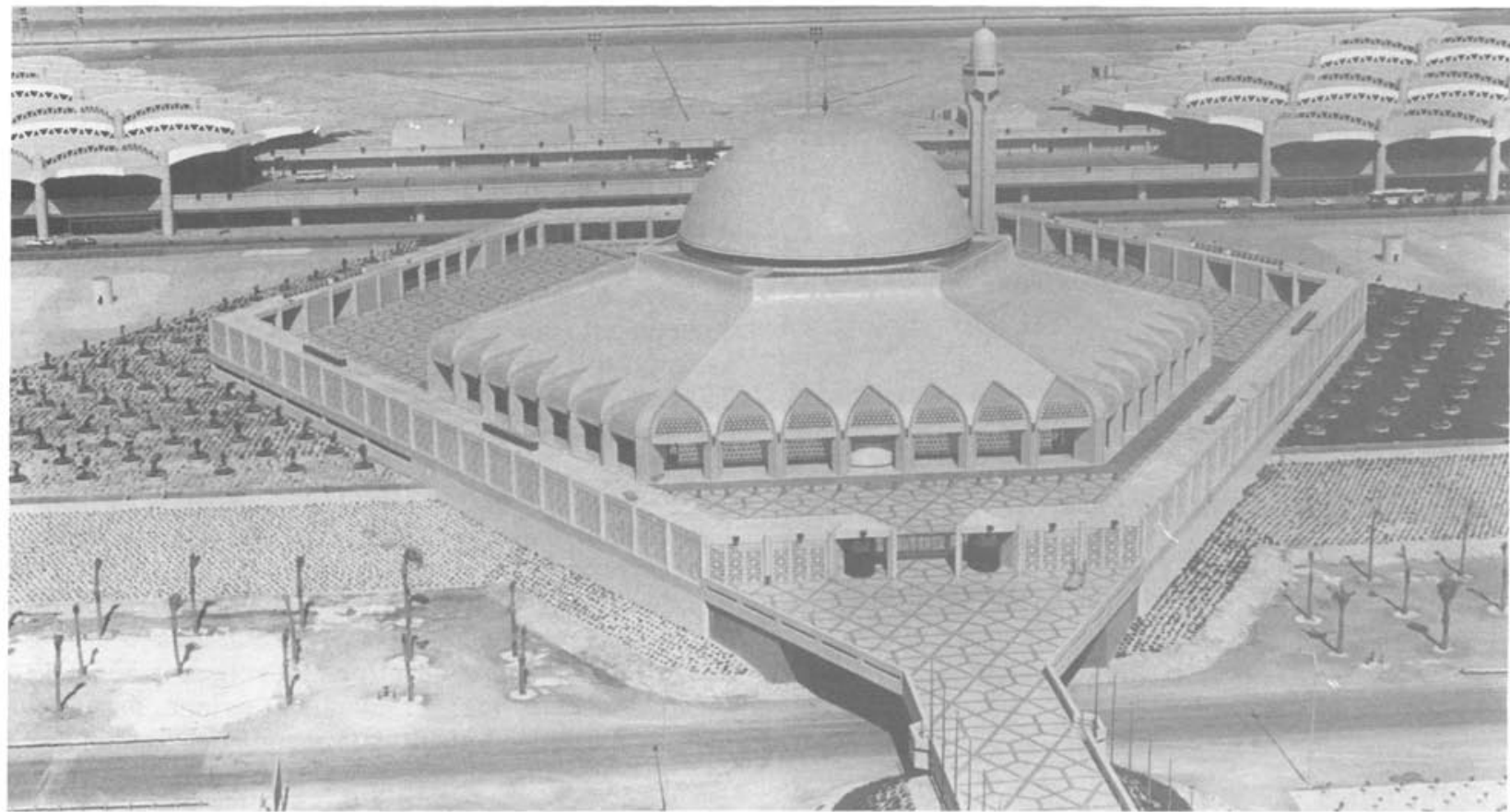

por 171 chalets, 219 apartamentos, 124 viviendas, mezquita y escuelas.

El aeropuerto tiene capacidad para unos 20 millones de pasajeros por año, capacidad más que suficiente de cara al futuro, ya que las previsiones para el año 2000 son sólo de 15 millones.

El complejo para la terminal de pasajeros incluye dos terminales nacionales y dos internacionales, conectadas por tres edificios de enlace. Cada una de las terminales es de planta esencialmente triangular con una superficie bruta de aproximadamente 47.500 metros cuadrados. El techo está compuesto por 72 secciones de bóveda esférica y forma triangular, de 24 metros de lado.

Cada uno de los edificios de enlace tiene 168 metros de longitud con una gran superficie de pasillo de aproximadamente 25.000 metros cuadrados. Los edificios contienen pasillos automáticos, restaurantes, cafeterias y oficinas de las compañias aéreas y del gobierno.

Una estructura de hormigón hecho in situ, de tres niveles, sirve de aparcamiento para los edificios terminales y la mezquita.

El pabellón real está situado en el extremo sur de la galería de ceremonias. Como las terminales de pasajeros tiene una planta triangular. La estructura del pabellón contiene 33 secciones triangulares de tejado, de 22 metros de lado cada una, con una superficie bruta de aproximadamente 28.500 metros cuadrados.

Entre el pabellón feal y la mezquita se encuentra una galería para ceremonias. Tiene 12,5 metros de ancho y aproximadamente 330 metros de largo.
La mezquita del aeropuerto dispone de una capacidad para aproximadamente 5.000 fieles en su interior. Está situada en el centro del complejo de terminales e incluye un minarete y una plaza para el culto exterior. La mezquita tiene una planta hexagonal de aproximadamente $51 \mathrm{me}$ tros de lado, con una superficie de unos 5.800 metros cuadrados. Su domo tiene una altura de 40,5 metros.

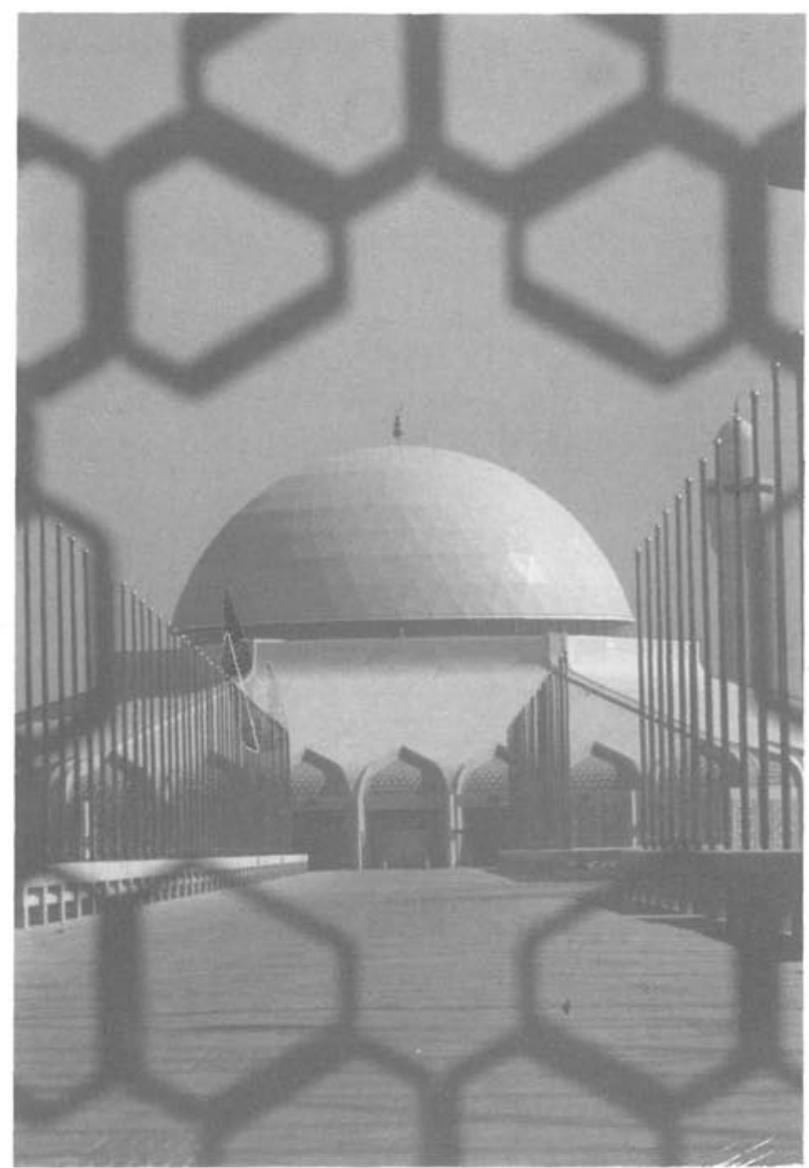



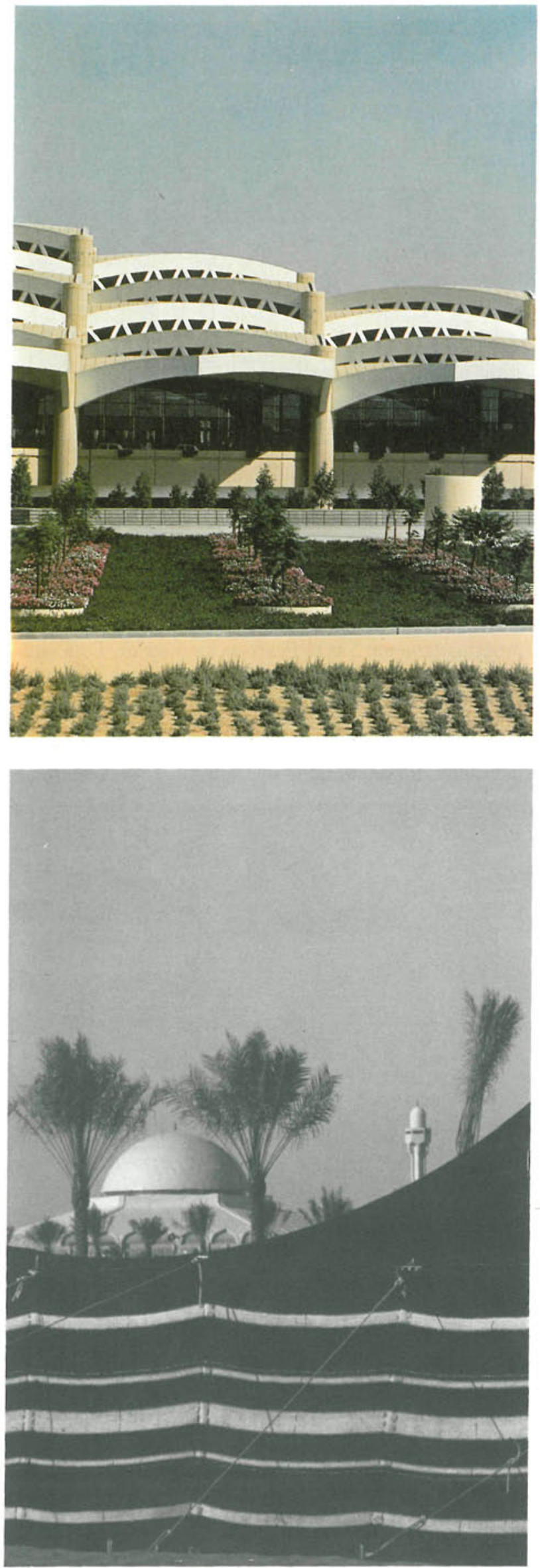

La torre de control del aeropuerto, con 81 metros de altura y una superficie de 1.230 metros cuadrados, es una de las más altas del mundo.

Los edificios auxiliares del aeropuerto incluyen un complejo para la administración central, un complejo para la sanidad pública, un cuartel general y dos auxiliares de bomberos, edificio de telecomunicaciones, correos, edificio para fletes aéreos, instalaciones meteorológicas, instalación para lanzamiento de globos, restaurante y concina central, tiendas de mantenimiento de equipos de apoyo terrestre, zonas de aparcamiento cubiertos y talleres, así como sección de mantenimiento de los equipos.

Las instalaciones de aterrizaje del aeropuerto incluyen dos pistas de 4.200 metros de longitud cada una y 60 metros de ancho, tres pistas de circulación paralelas, $\mathrm{y}$ otras 20 pistas de circulación más pequeñas. Dos pistas a través de las terminales, de aproximadamente 1.800 metros de longitud cada una, permiten a los aviones pasar de un lado a otro del aeropuerto por encima del sistema de carreteras del edificio principal. El aeropuerto tiene cuatro playas de estacionamiento: la de la terminal de pasajeros, de $430.000 \mathrm{~m}^{2}$; la de carga, de $64.000 \mathrm{~m}^{2}$; la de la terminal real, de $67.000 \mathrm{~m}^{2}$; y la de aviación general, de $96.000 \mathrm{~m}^{2}$.

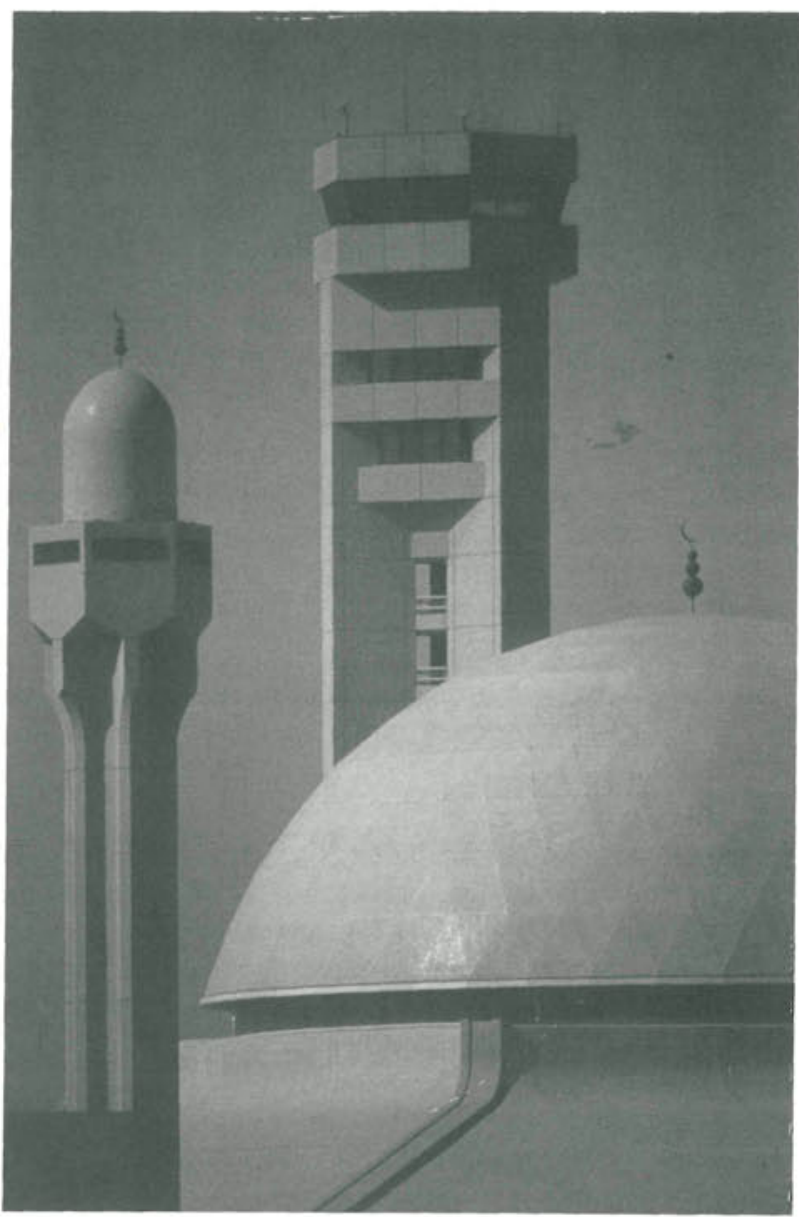


El aeropuerto dispone de diez puentes para carreteras con una longitud total de aproximadamente 1.260 metros. Estos puentes tienen una longitud que oscila entre 28 y 346 metros y una anchura comprendida entre 9,9 y 26 metros.

La autopista de acceso al aeropuerto es una calzada dividida en cuatro carriles pavimentados (en su último tramo consta de 6 carriles) de aproximadamente 32 kilómetros de longitud dentro de los limites del aeropuerto. En el interior del complejo terminal hay 13,7 kilómetros de rampas de un carril y 4,2 kilómetros de rampas de dos carriles.

\section{Mezquita del aeropuerto}

La hermosa mezquita que domina el horizonte del aeropuerto internacional King Khaled es considerada por muchos como una de las nuevas estructuras religiosas más interesantes del Oriente Medio.

Sólo desde el punto de vista estadístico, sus dimensiones son impresionantes. Puede recibir a 5.000 devotos en su interior y otros 3.000 ó 4.000 en la plaza exterior.

En términos de estética, sus franjas de mármol tallado, sus ventanas y claraboyas de cristal de color, sus motivos complicados de azulejos de cerámica y sus puertas y
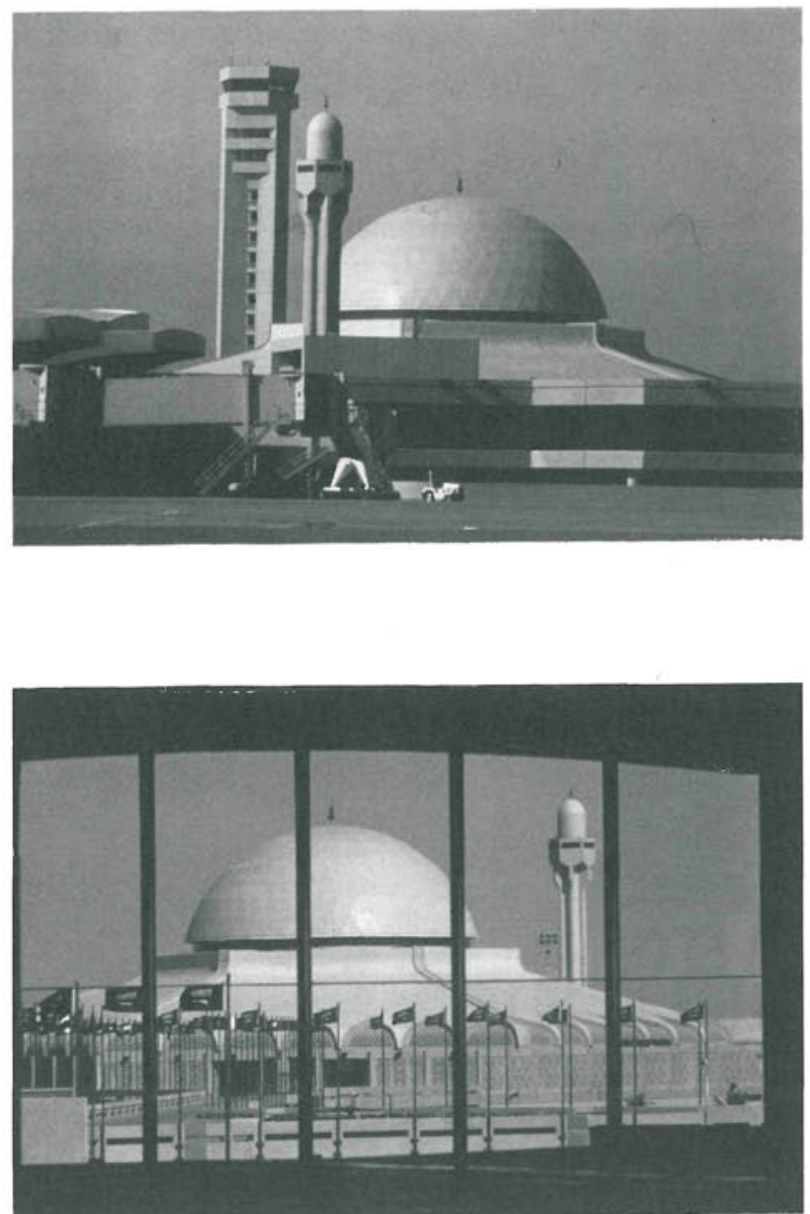
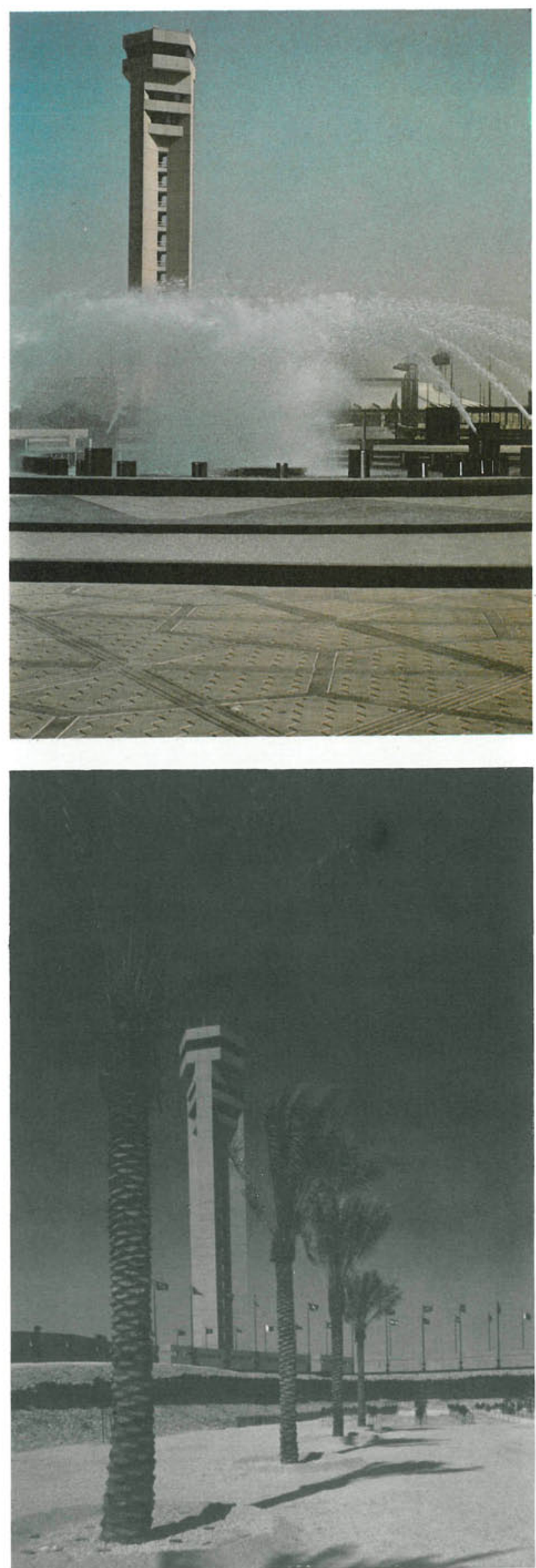

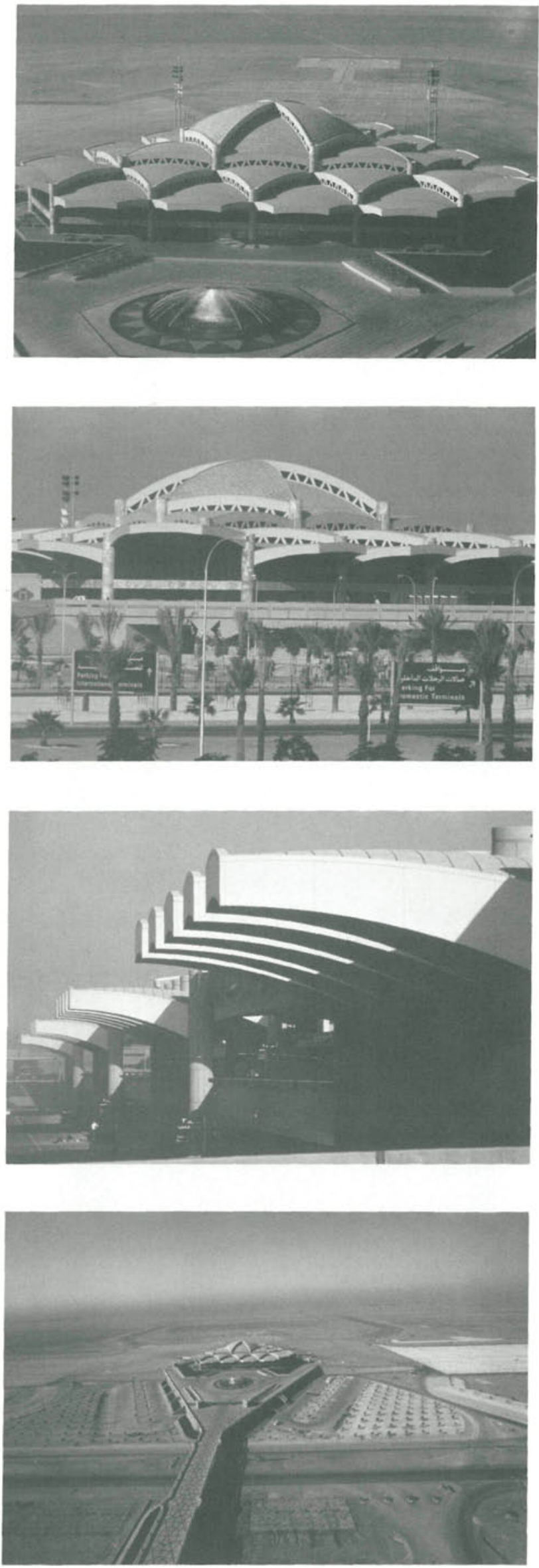

ventanas de madera tallada la convierten en una atracción del arte tradicional islámico. Y su ubicación en el centro de la terminal de pasajeros hacen de ella la estructura más importante del aeropuerto y es lo primero que los visitantes ven cuando abandonan las zonas de llegada.

El domo tiene 33 metros de diámetro y las torres están a 40 metros por encima del nivel de las carreteras de llegada, más altas que las demás estructuras del complejo de pasajeros con excepción de la torre de control y el minarete.

Una franja de dos metros de altura de galería de cristal separa el domo del suelo de la mezquita y da la impresión de que el domo está flotando por encima del techo. En el interior los rayos del sol se filtran a través de los vidrios de color e iluminan el interior con una luz suave ámbar y azul.

Para llegar a la plaza de la mezquita, el visitante tiene que subir por una amplia escalera ceremonial. Los 46 peldaños de granito tienen 60 metros de ancho en la base, terminando con un ancho de 42 metros en su parte superior. También existen dos escaleras mecánicas, una a cada lado de la escalera, para subir al nivel de la plazạ.

El domo y el techo inferior están recubiertos con losetas de cerámica triangulares de colores, unidas a vigas de acero. En el interior, 1.008 paneles de bronce encajan dentro del domo, por encima de un anillo de mosaicos decorativos con pasajes del Corán.

El domo lo sostiene una red de columnas de acero y armazones, asegurada por el tejado inferior. Desde el centro del domo cuelga un candelabro con 96 luces de colores, montadas en un aro de bronce de 13 metros de diámetro, que proyectan una luminosidad suave sobre la zona de oraciones a la caída de la noche.

En la esquina noreste de la plaza de la mezquita se alza un minarete a 39 metros por encima del nivel de la plaza. Una escalera de caracol interior permite el acceso a los altavoces a través de los cuales se hacen las llamadas diarias para la oración.

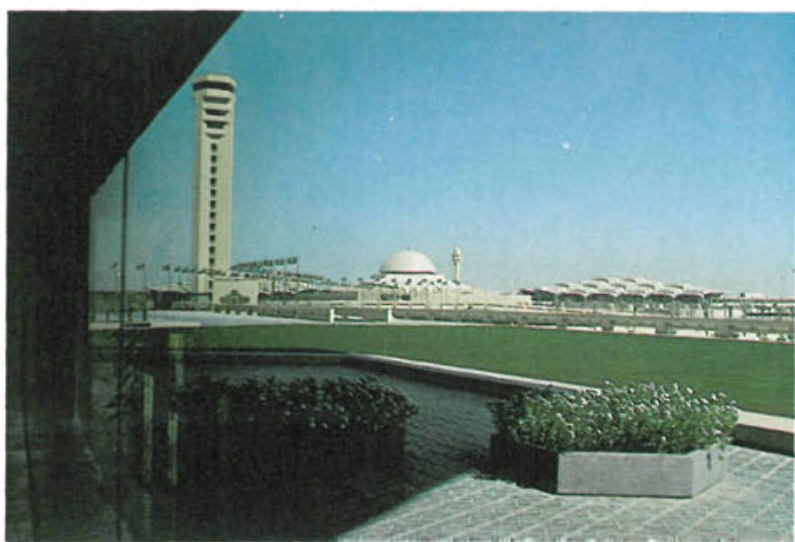


La mezquita tiene 5.030 metros cuadrados de superficie principal en la planta baja y 765 metros cuadrados en el entresuelo. Una librería coránica situada fuera de la superficie principal de la mezquita dispone de 50 metros cuadrados de superficie para usuarios y la misma cantidad de almacenamiento.

Los muros exteriores e interiores de la mezquita van revestidos de mármol travertino de Italia. El travertino interior fue enviado a Inglaterra donde se grabaron pasajes del Corán en caligrafia Koufic, antes de enviarlo a Riyadh. El mármol exterior se decoró en Italia con grabados florales.

Los pisos interiores son de travertino y granito y los de la plaza de bloques ajustados de piedra machacada.

\section{Pabellón real}

Los Jefes de Estado, así como los visitantes de alto rango en el Reino, serán recibidos en el pabellón real, fiel reflejo de la cultura y belleza del Islám.

El pabellón real, edificio distinguido de fuerte carácter islámico, tiene grandes espacios arquitectónicos, materiales y acabados finísimos, frondosas zonas ajardinadas y fuentes refrescantes. Una galeria de ceremonias de 12,5 metros de ancho por 330 metros de largo lo conecta con la mezquita. El diseño y geometría del edificio son similares a los de las demás terminales del complejo para pasajeros. Pero el pabellón real tiene un carácter y una calidad que hace de él una estructura muy especial en la jerarquia de edificios del complejo.

Los visitantes que llegan pueden utilizar escaleras aéreas o mecánicas para entrar en el edificio desde las pistas de aterrizaje. La zona de ceremonias, en la parte de aterrizaje, tiene un espacio reservado para recepciones especiales con guardias de honor y bandas de música.

$\mathrm{Al}$ igual que las terminales de pasajeros, el pabellón real posee una planta triangular con un tejado que consta de 33 secciones en arco que asciende hasta la cúspide, situada a 30 metros por encima del nivel del suelo. Las paredes y ventanas de cristal entre las secciones del techo permiten la iluminación del interior del edificio con luz natural.

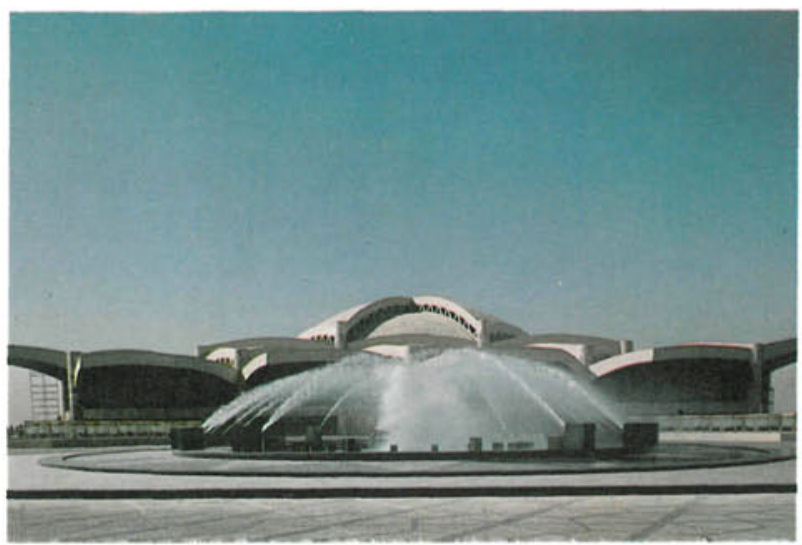

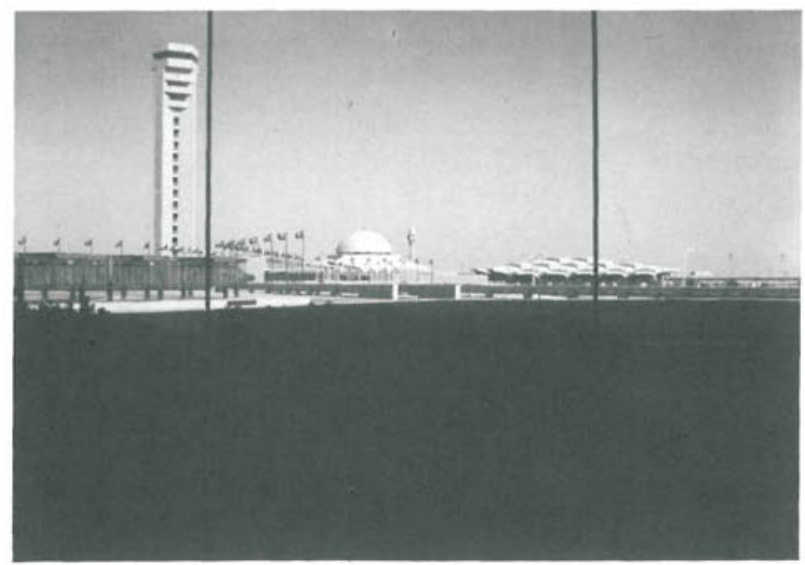
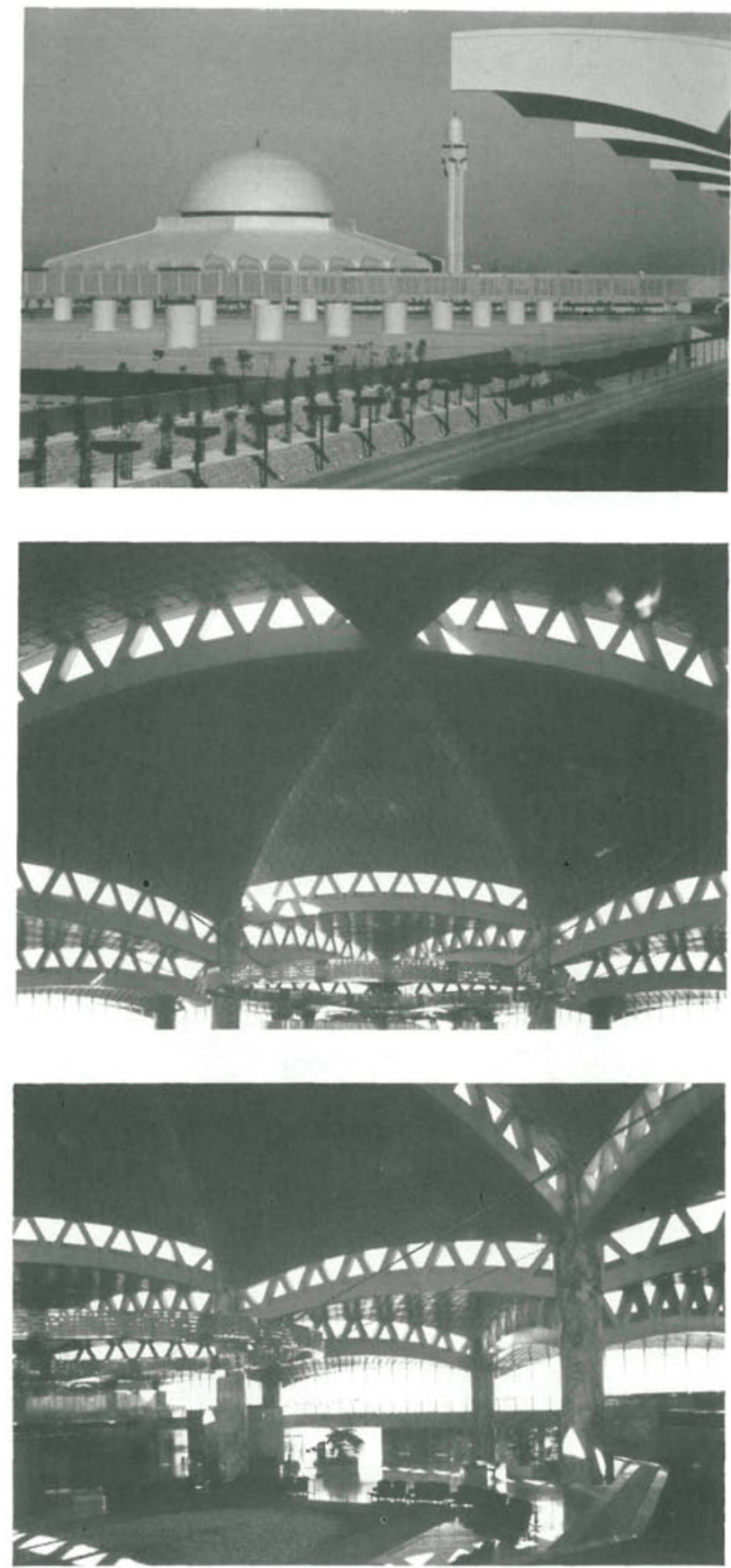

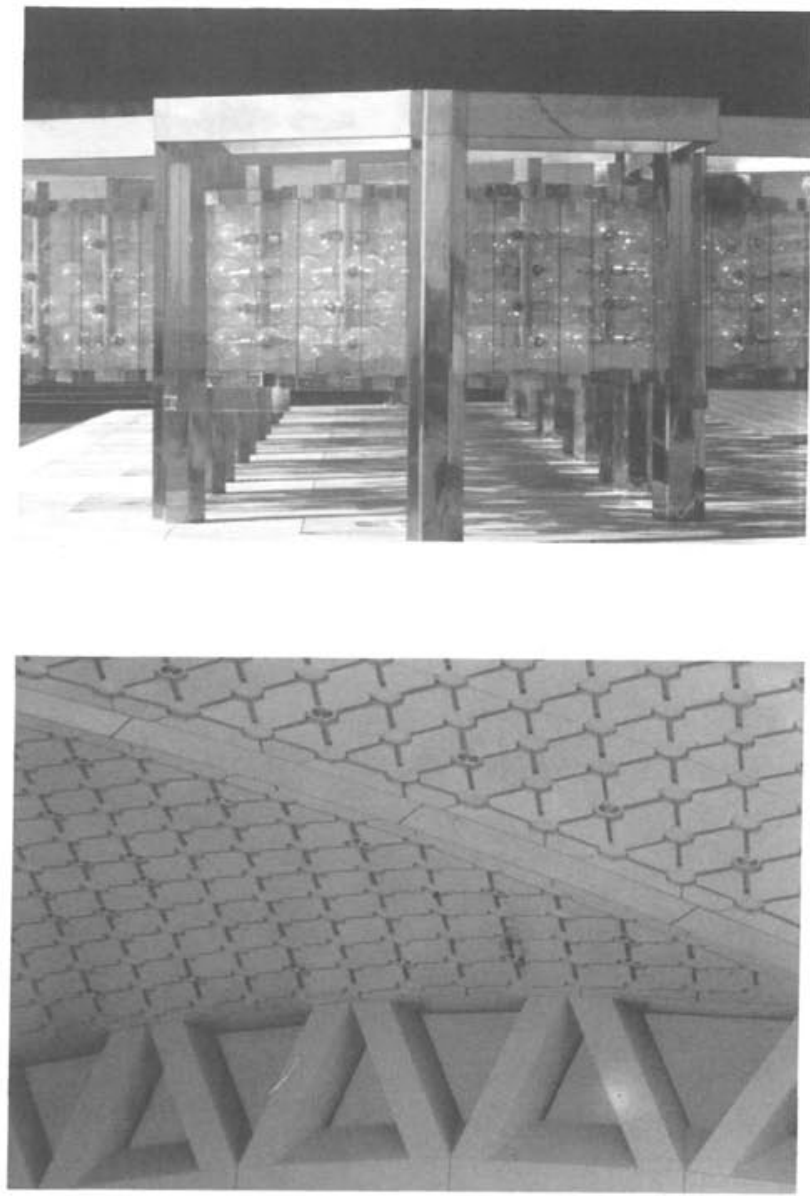

Los tres niveles de la estructura facilitan todo lo necesario para la atención a los visitantes y personal. A nivel de la plaza se encuentra la sala de recepción principal y la de recepción real, así como una suite real, un auditorio para la prensa, oficinas y una cocina.

El nivel intermedio proporciona espacio para funciones de soporte, como administración de terminales, seguridad, equipaje y operaciones de vuelo, así como para el equipo mecánico y eléctrico.

En el nivel inferior se encuentran los vestibulos para pasajeros, zonas para reclamación de equipajes, una oficina de prensa y oficinas para los oficiales de inmigración, aduanas y sanidad.

El aparcamiento a dos niveles ofrece sitio para más de 400 coches. Se dispone de 100 lugares más en el patio de entrada, a nivel de la plaza y muchos espacios más en las zonas ajardinadas a lo largo de la estructura del aparcamiento. En total se cuenta con aproximadamente 800 plazas dentro y alrededor del pabellón.

\section{La torre de control}

Situada en el centro, en el complejo de la terminal de pasajeros entre el pabellón real y la mezquita, se encuentra la torre de control de tráfico aéreo del aeropuerto. Con sus 81 metros de altura, es una de las torres de control más altas del mundo.

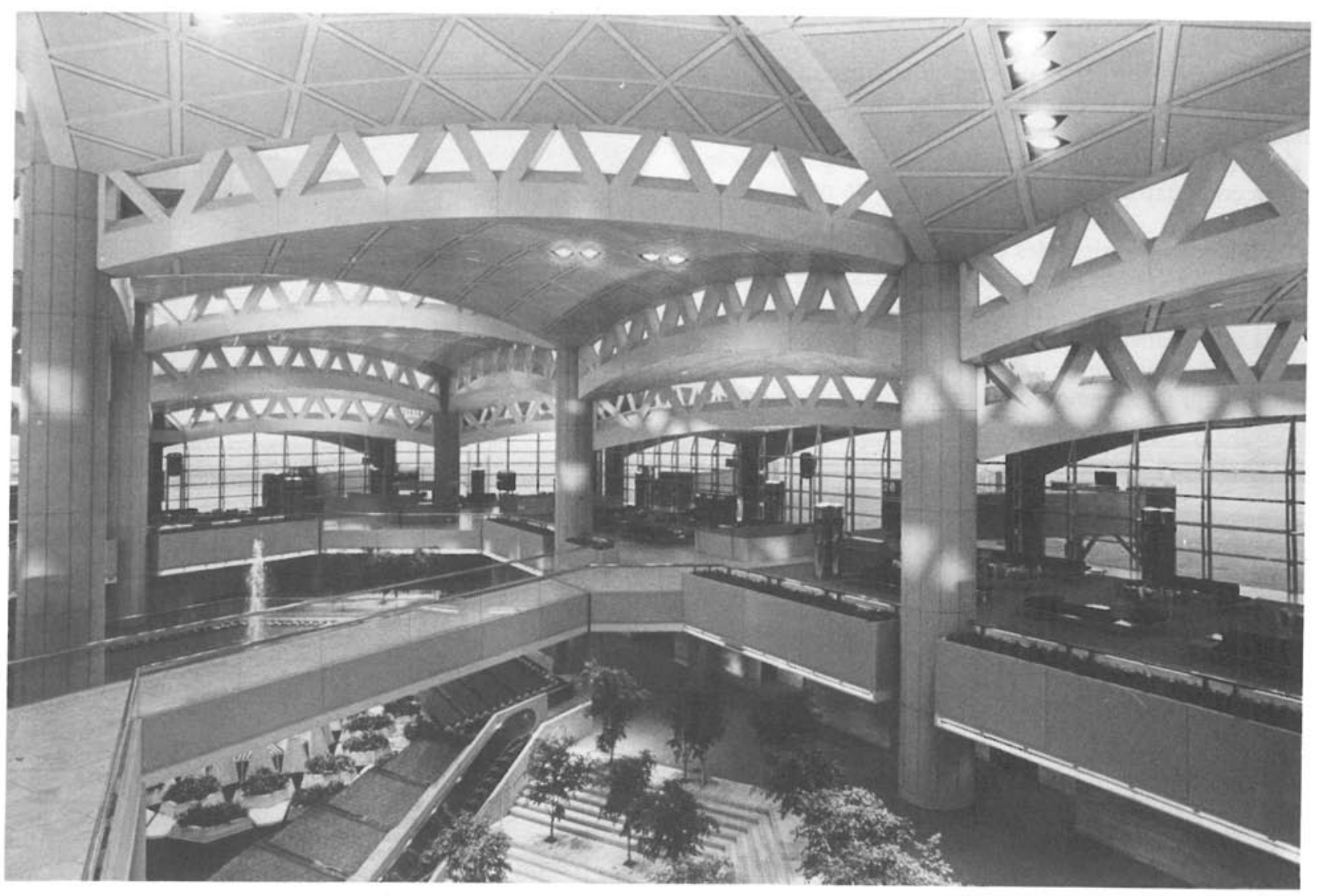




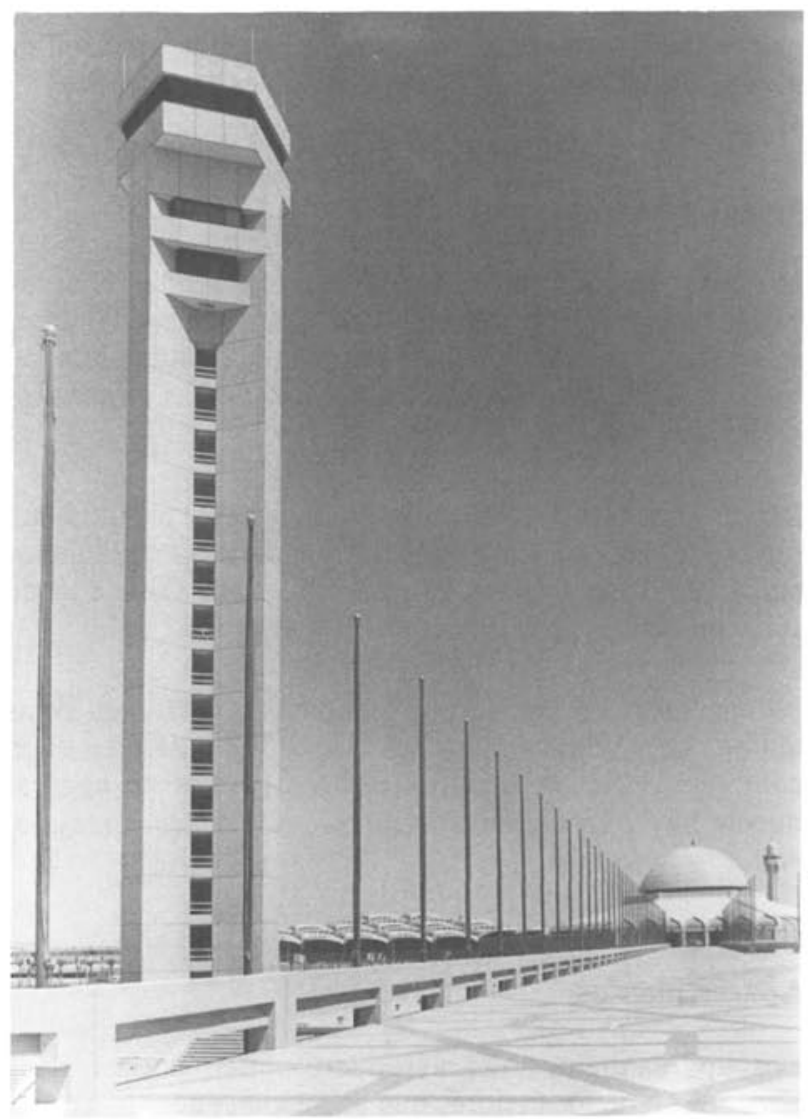

La torre tiene 19 niveles, incluyendo la zona de operaciones en la base de la misma, y un total de 1.230 metros cuadrados de superficie.

De las 19 plantas, las principales son: la de nivel operativo en la base de la torre, que incluye el centro de control por radar del aeropuerto, así como salas de conferencias, oficinas y una zona de enseñanza, dos plantas para equipos, una de observación, otra de servicio y la planta situada en la parte superior de la torre, desde la cual los controladores de tráfico aéreo dominan todo el aeropuerto.

\section{Puentes aéreos de enlace}

Este aeropuerto es el primero del Reino que dispone de puentes aéreos para facilitar el acceso directo de los pasajeros desde la terminal hasta el avión.

Las terminales nacionales e internacionales tienen 8 puentes aéreos cada una y el pabellón real dispone de 2 . Los puentes pueden utilizarse para cualquier tipo de avión. Ofrecen un acceso inmediato de los pasajeros a su avión desde el vestibulo de salida de la terminal.

Los puentes aéreos de las terminales nacionales e internacionales tienen secciones basculantes telescópicas que pueden subirse o bajarse o moverse lateralmente hasta adaptarse a la posición de la puerta del avión.
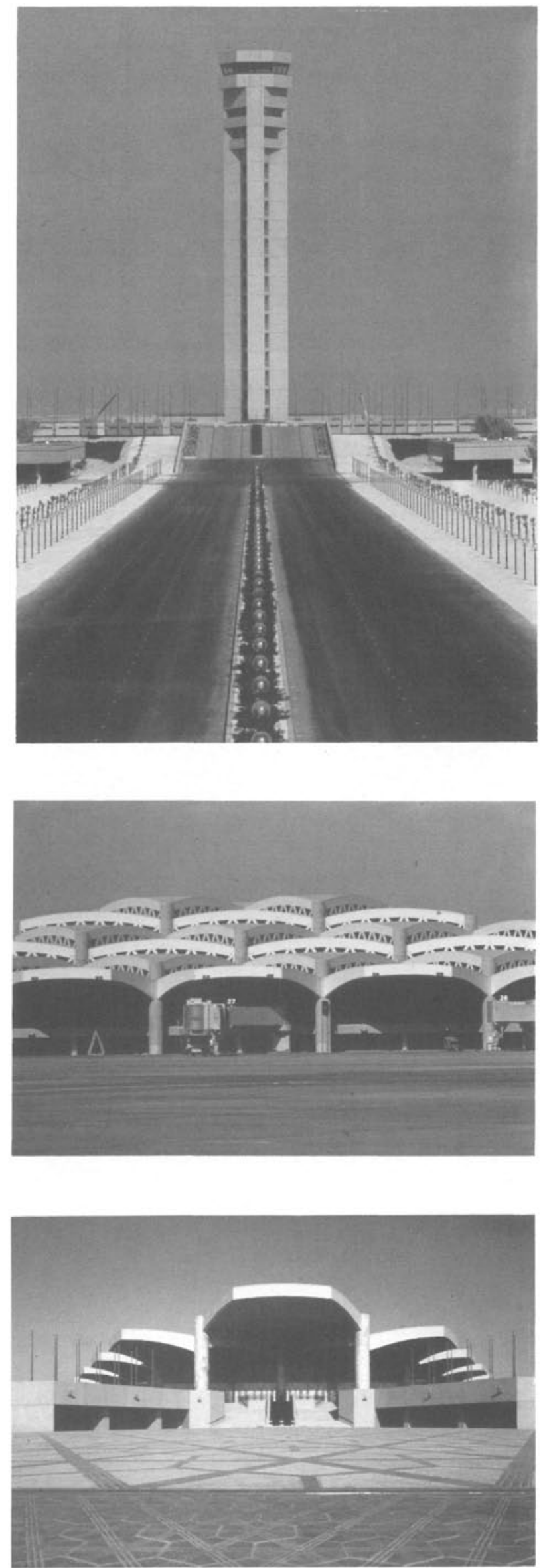

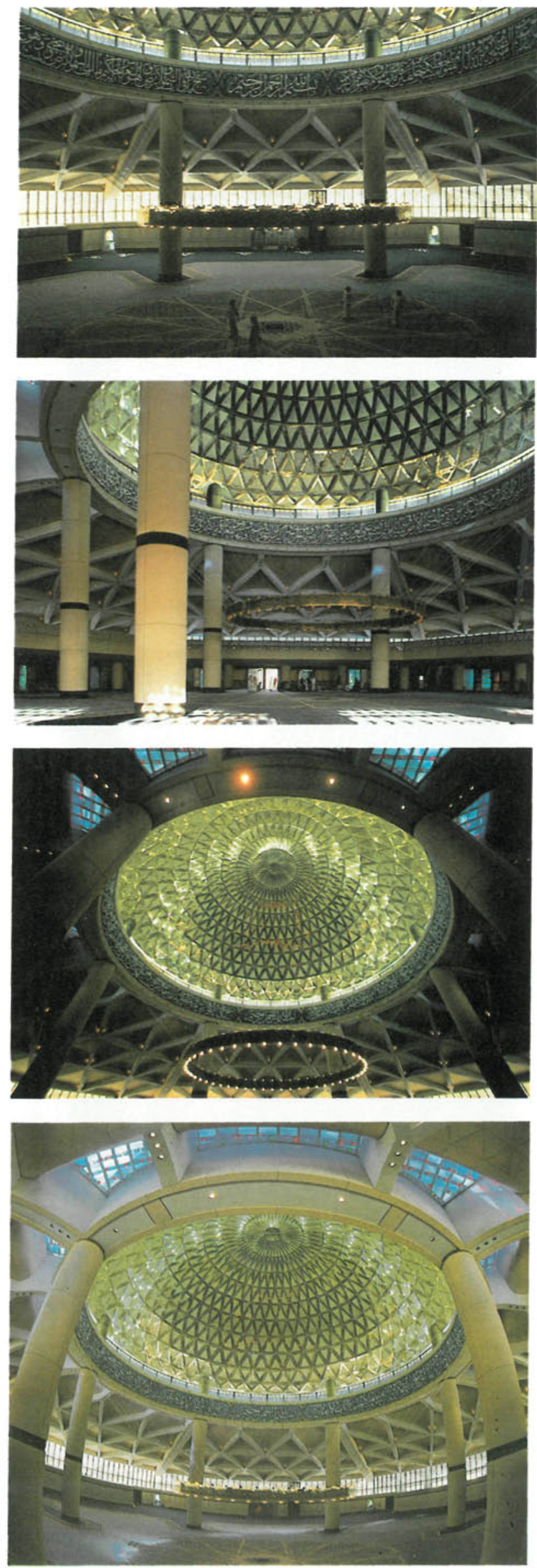

Los puentes son de construcción ignifuga. Además cada puente va provisto de un sistema de aspersión que facilita protección adicional en el caso de incendio.

\section{Aceras y escaleras mecánicas}

Los pasajeros que van de una terminal a otra en el aeropuerto encuentran "aceras mecánicas» que les facilitan un tránsito rápido. Las aceras mecánicas están situadas en los tres edificios de enlace que conectan las terminales nacionales e internacionales.

Existe un total de 1.196 metros de aceras, pasillos que son realmente amplias cintas transportadoras que funcionan a nivel del suelo y se mueven a una velocidad de aproximadamente de un metro por segundo.

80 ascensores y escaleras mecánicas constituyen otras tantas comodidades a disposición de los pasajeros en el complejo de las terminales. En los garajes de aparcamiento hay 16 escaleras mecánicas, dos de las cuales llevan a la mezquita.

\section{Aparcamientos}

Los aparcamientos del aeropuerto internacional King Khaled son de los mejores que se pueden encontrar en un aeropuerto internacional.

Se ha construido, directamente frente a las terminales de pasajeros, dos amplios garajes de 3 niveles, uno a cada lado de la mezquita. Están unidos con las terminales y la mezquita por pasillos peatonales situados por debajo del nivel de la carretera de llegadas.

-La capacidad proyectada de los garajes es de 11.600 vehículos. Unos 8.000 vehículos pueden aparcarse en los dos niveles cubiertos y otros 3.600 coches en el nivel descubierto del tejado.

Cerca de las terminales se ha construido una zona especial de aparcamiento, que puede recibir a otros $360 \mathrm{co}-$ ches, destinada a minusválidos, visitantes especiales, personal de seguridad y administradores del aeropuerto. Las agencias de alquiler de vehículos tendrán también acceso a esta zona.

Los garajes son de hormigón hecho in situ. Cada uno de los niveles cubiertos tienen 4 metros de altura. Los viajeros disponen de escaleras mecánicas y ascensores, así como de escaleras entre los diversos niveles.

\section{Obras artísticas del nuevo aeropuerto}

Algunas de las labores artísticas más destacadas del Reino de Arabia Saudita se pueden ver en el nuevo aeropuerto internacional de la capital. 
Pinturas, tapicerias, esculturas, alfombras orientales y mosaicos, se encuentran entre los centenares de obras de arte que se exponen en las terminales y otros edificios públicos, incluso en la mezquita.

\section{Ajardinamiento y paisaje}

Además de ser el más reciente aeropuerto del mundo, King Khaled International -con sus más de 50 hectáreas de jardines y espacios verdes - constituye la atracción turística más reciente del Reino.

Se utilizaron más de 225.000 arbustos de enredadera y plantas pequeñas para adornar el aeropuerto y los patios interiores. Casi todas estas plantas proceden de los propios viveros del aeropuerto.

De acuerdo con un amplio plan, el programa de configuración paisajista del aeropuerto fue diseñado para realzar fisicamente el lugar y proporcionar comodidad e interés visual en el medio ambiente desértico.

Cada una de las instalaciones importantes posee elementos de jardineria adaptados a su estructura física, escala dimensional y tipo de ocupación. Por ejemplo, dentro de los terminales del aeropuerto, el viajero se ve recibido por un despliegue de agua, flores y árboles, diseñado para ser admirado a corta distancia por los peatones. Fuera de las terminales, el paisaje se basa principalmente en grandes árboles que se pueden ver desde el aire o desde los coches que van circulando.

Otro factor que tuvo una importancia decisiva en la configuración del paisaje fue la disponibilidad limitada de agua para riego. La mayoria del agua que se utiliza para el riego procede de la planta de depuración de aguas residuales. Un sistema automático emisor de agua subterránea se utiliza en todo el aeropuerto para permitir una infiltración lenta a través de la base y minimizar al mismo tiempo la evaporación.

Los jardines del aeropuerto y las zonas ajardinadas no solamente sirven para embellecer la zona. Ayudan a estabilizar el suelo, a reducir los efectos de las fuertes ráfagas de viento y proporcionan una protección contra el soli y para el lugar. Esto es cierto tanto en el interior de los patios como en las zonas exteriores. El follaje de los árboles en los patios desvía los vientos sin obstaculizar la circulación del aire, proporciona sombra y frescor, alivio visual respecto del sol y suaviza los ruidos producidos por el tráfico aéreo.

Otra de las características del programa de configuración del paisaje es su facilidad de mantenimiento. Con la excepción del pabellón real y las instalaciones comunitarias, no hay ningún césped que cuidar. Además, las zonas con plantas pequeñas se utilizan únicamente cuando es necesario para la estabilización de las laderas y para ofrecer un mayor cromatismo en las terminales y otras zonas especiales. La característica principal del proyecto la constituyen los árboles, debido a su relativamente reducida necesidad de mantenimiento y a su impacto visual.
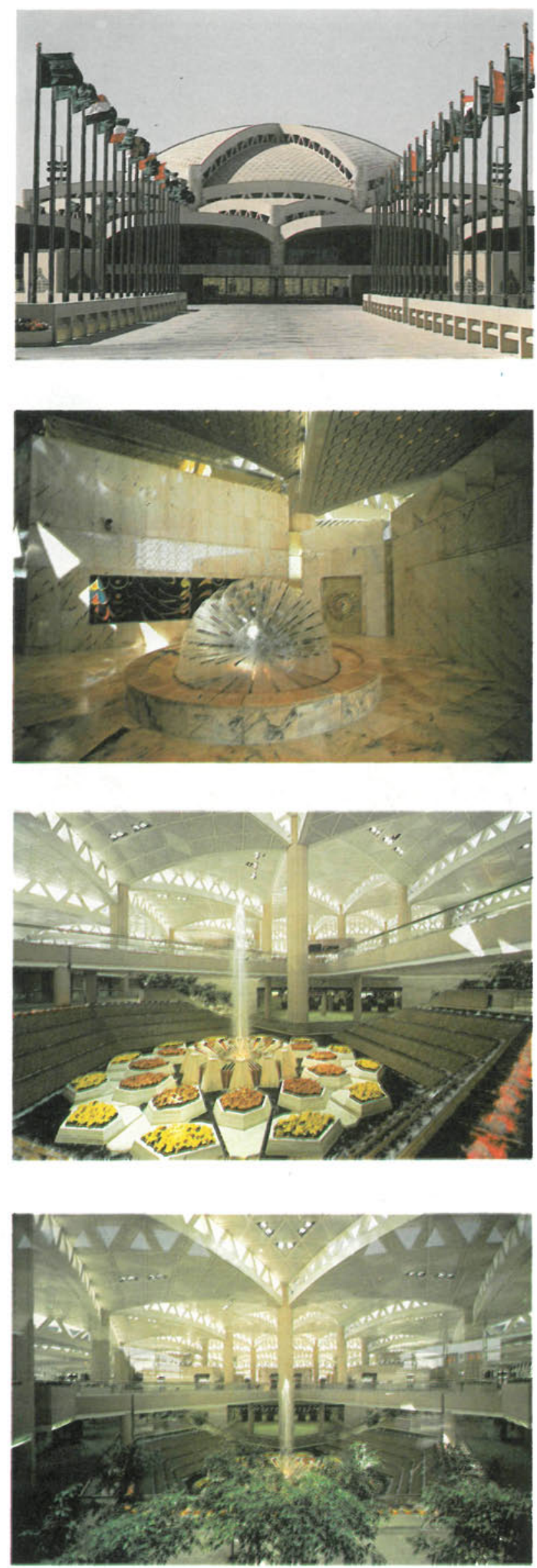


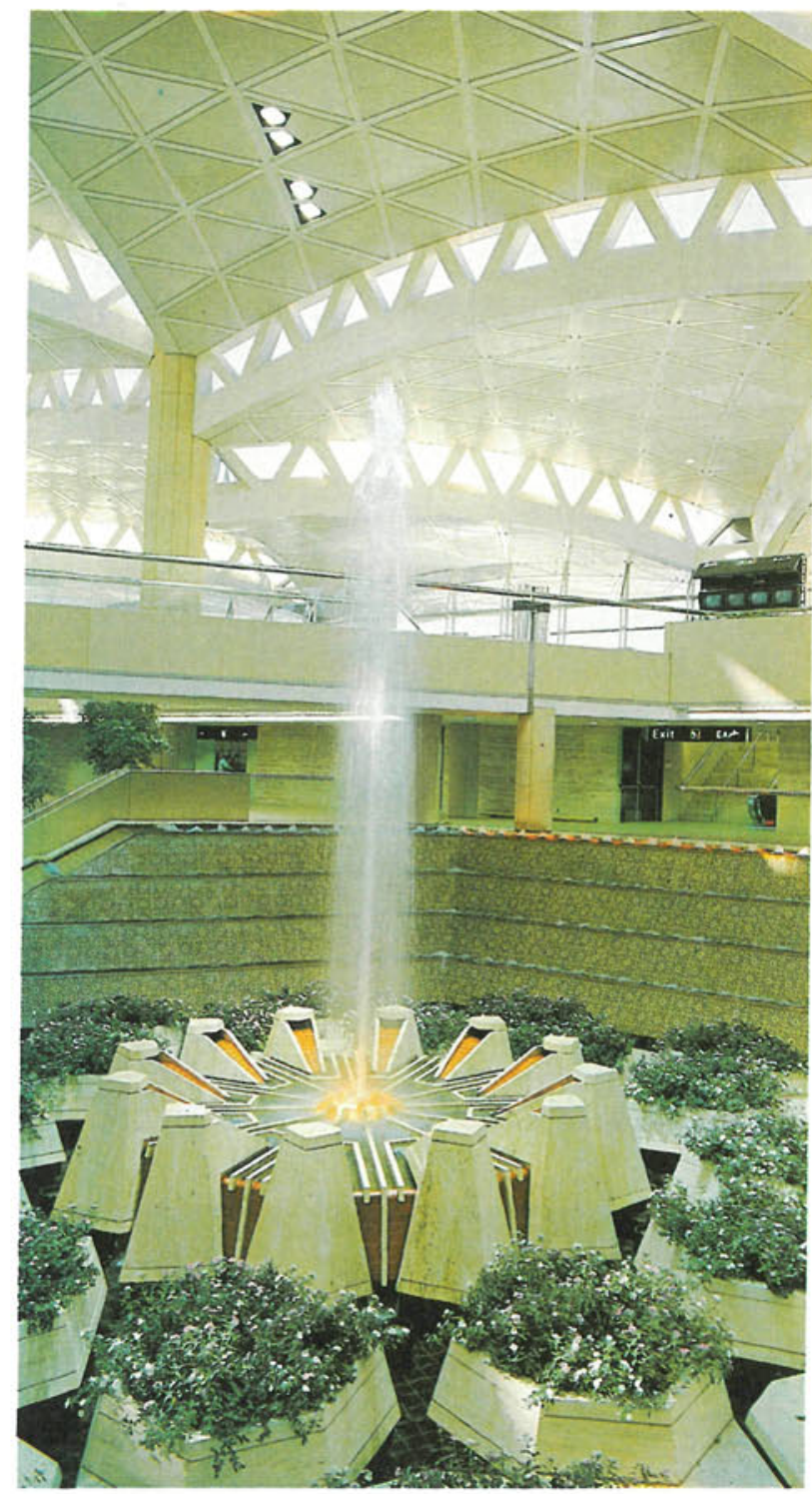

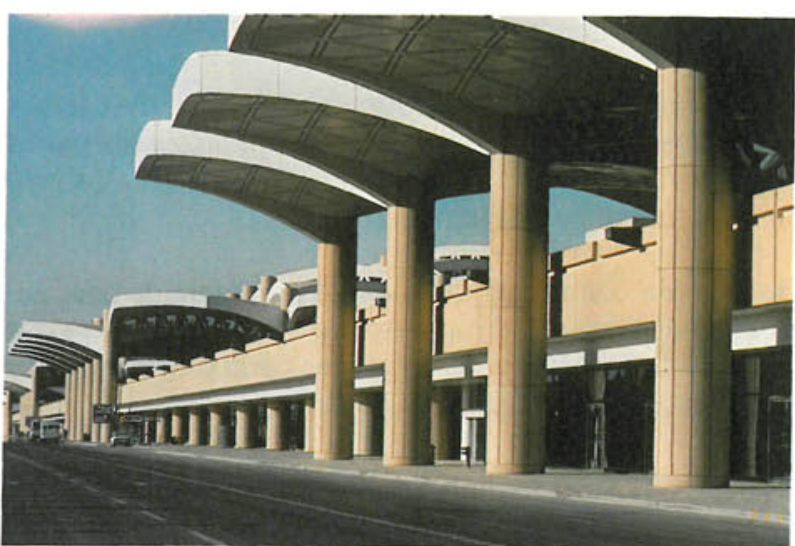

Evidentemente la más espectacular formación floral se encuentra en las terminales de pasajeros en las que unos grandes jardines interiores con flores y fuentes constituyen el punto focal de cada terminal. Grupos terraplenados de árboles y enredaderas de colgantes bajos se combinan para ofrecer un impacto visual sorprendente a los pasajeros.

Aunque la zona en la que está situada el aeropuerto es llana y los horizontes distantes, la arquitectura solemne de los edificios combinada con la fuerte ordenación visual del programa paisajista han producido una imagen penetrante de hospitalidad y constituyen una puerta de acceso refrescante a la capital del Reino. 